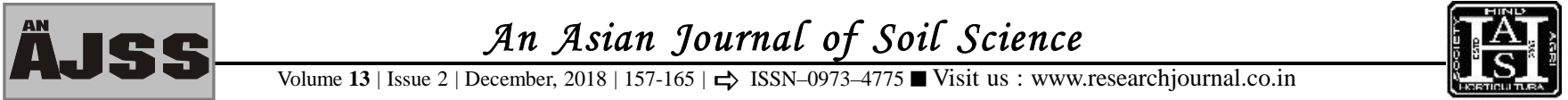

\title{
Fundamental of siderophores in soil
}

\author{
Kabir Debbarma and N.J. Singh
}

Received : 10.10.2018; Accepted : 26.11.2018

MEMBERS OF RESEARCH FORUM:

Corresponding author :

Kabir Debbarma, College of Post

Graduate Studies (C.A.U.), Umiam

(Meghalaya) India

Email: kabirdb90@gmail.com

Co-authors :

N.J. Singh, College of Post

Graduate Studies (C.A.U.), Umiam

(Meghalaya) India

\section{Summary}

Iron is one of the important factors and essential nutrients of microbial life. Micro-organisms and plants produce small high affinity chelating molecules known as siderophore. Siderophore also play a critical role in microbial life and plant metabolism activity. Apart from maintaining microbial life, siderophore can be harnessed for the sustainability of human and animals. Siderophore have the ability to bind trace metals and toxic heavy metals. Even though siderophore form complexes with heavy metals, unlike Fe it restrains they deliver through the plasma membrane of the root cells. Thereby siderophore reduce the metal accumulation in the plant. A great variation is seen in siderophore structure produced by many bacteria. There are three main kinds of siderophore known as hydroxamate, catecholate and carboxylate. Siderophore production can be obtained under iron restrict media and many researchers have produced siderophore from bacteria on succinate media. Siderophore and their derivative have large application in agriculture as to increase soil fertility and biocontrol for fungal pathogen. Siderophore also used to reduce the level of metal contamination in environment specifically from soil and water.The bacterium Bacillus megaterium is known to produce two hydroxamate siderophore, schizokinen and N-deoxyschizokinen, under iron-limited conditions.

Key words : Siderophore, Rhizosphere, Phytosiderophore, Iron, Micro-organisms, Heavy metal

How to cite this article : Debbarma, Kabir and Singh, N.J. (2018). Fundamental of siderophores in soil. Asian J. Soil Sci., 13 (2) : 157-165 : DOI : 10.15740/HAS/AJSS/13.2/157-165. 